\title{
Alcohol-Induced Wernicke-Korsakoff's Syndrome
}

National Cancer Institute

\section{Source}

National Cancer Institute. Alcohol-Induced Wernicke-Korsakoff's Syndrome. NCI

Thesaurus. Code C34366.

A syndrome which occurs in individuals with a history of alcohol abuse. It is caused by prolonged alcohol-induced neurological damage and malnutrition including vitamin and electrolyte deficiencies. Clinical signs include altered mental status, visual impairment and decreased muscle coordination. The clinical course varies and is, in part, dependent upon the severity of symptoms at presentation. The prognosis is poor and worsens if alcohol abuse continues. 